\title{
DESIGN AND CONSTRUCTION OF SOLAR TRACKING CONTROL SYSTEM
}

\author{
*Rashwan M. A., *Jailany A.T.
}

\begin{abstract}
The increasing demand for energy, the continuous reduction in existing sources of fossil fuels and the growing concern regarding environment pollution, have pushed mankind to explore new technologies for the production of electrical energy using clean, renewable sources, such as solar energy, wind energy, etc. Renewable energy is considered safe and sustainable way to get clean energy and reduce dependence on traditional energy sources. Solar energy is gaining increasing importance; especially in Egypt because of the vast areas and large periods of brightness, making it contributes a large share of the energies used. Convert solar energy into electrical energy using solar cells is still expensive and ineffective. It is applied to different mechanisms for increasing the efficiency of solar cells to reduce costs. Solar tracking system is the most appropriate technology to enhance the efficiency of solar cells by tracking the sun. Thus, this paper deals with controlling the solar panel at two axes by using four light dependent resistor (LDRs) as sensors, stepper and direct current (DC) motors as actuators (M1, M2) and microcontroller PIC16F877A as a controller unit. The prototype of solar tracking system has a mechanism for precise control to keep tracking of sun automatically and get the largest possible energy on the solar cell. Results have proven that, the model has high accuracy in tracking the movement of the sun throughout the day.
\end{abstract}

\section{INTRUDUCTION}

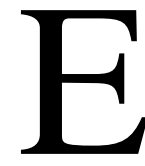
nergy crisis is the most important issue in today's world and especially in Egypt, where the increase in population on the one hand and the lack of fuel and gas with increased consumption as a result of increased growth in all areas (Md. Tanvir Arafat K. et al., 2010).

*Assist. Prof. Agric. and Biosystems Eng. Dept., Fac. of Agric. (El-Shatby), Alexandria University. 
Renewable energy sources play an important role in electric power generation. There are various renewable sources which used for electric power generation, such as solar energy, wind energy, geothermal etc. (El-Ashry M., 2010). Solar Energy is a good choice for electric power generation, since the solar energy is directly converted into electrical energy by solar photovoltaic modules (Parallax, 2004).

Increasing the cell efficiency, maximizing the power output and employing a tracking system with solar panel are three ways to increase the overall efficiency of the solar panel (Piao, Z.G. Park et al., 2005). Main factors that affect the efficiency of the collection process are solar cell efficiency, intensity of source radiation and storage techniques.

The efficiency of a solar cell is limited by materials used in solar cell manufacturing. It is particularly difficult to make considerable improvements in the performance of the cell, and hence restricts the efficiency of the overall collection process. Therefore, the increase of the intensity of radiation received from the sun is the most attainable method of improving the performance of solar power. There are three major approaches for maximizing power extraction in solar systems. They are sun tracking, maximum power point (MPP) tracking or both (Tse K. K., et al., 2002).

The conversion of solar light into electrical energy represents one of the most promising and challenging energetic technologies, in continuous development, being clean, silent and reliable, with very low maintenance costs and minimal ecological impact. Solar energy is free, practically inexhaustible, and involves no polluting residues or greenhouse gases emissions (Tiberiu Tudorache1 and Liviu Kreindler, 2010).

The applications for solar energy in recent years are increased rapidly, and that need to improve the materials and methods used to harness this power source (Clean Energy Decision Support Centre, 2001 - 2004).

The sun is the prime source of energy, directly or indirectly, which is also the fuel for most renewable systems. Among all renewable systems, photovoltaic system is the one which has a great chance to replace the conventional energy resources. Solar panel directly converts solar radiation into electrical energy. Solar panel is mainly made from 
semiconductor materials. Silicone (Si) used as the major component of solar panels, which is maximum $24.5 \%$ efficient (Md. Tanvir Arafat K. et al., 2010). The conversion principle of solar light into electricity, called Photo-Voltaic or PV conversion, is not very new, but the efficiency improvement of the $\mathbf{P V}$ conversion equipment is still one of top priorities for many academic and/or industrial research groups all over the world (Tiberiu Tudorache and Liviu Kreindler, 2010). Unless high efficient solar panels are invented, the only way to enhance the performance of a solar panel is to increase the intensity of light falling on it. A solar panel receives the most sunlight when it is perpendicular to the sun's rays, but the sunlight direction changes regularly with changing seasons and weather. Currently, most solar panels are fixed, i.e., the solar array has a fixed orientation to the sky and does not turn to follow the sun. To increase the unit area illumination of sunlight on solar panels, we designed a solar tracking electricity generation system (Zhang Xinhong, 2007). Solar trackers are the most appropriate and proven technology to increase the efficiency of solar panels through keeping the panels aligned with the sun's position. Solar trackers get popularized around the world in recent days to harness solar energy in most efficient way. This is far more cost effective solution than purchasing additional solar panels (M.A. Panait and T Tudorache, 2008).

Generally, solar panels are stationary and do not follow the movement of the sun, while in this research, a solar tracker system tracks the sun's movement across the sky and tries to maintain the solar panel perpendicular to the sun's ray, Ensuring that the maximum amount of sunlight is incident on the panel throughout the day till evening. (Joydev Ghosh et al., 2013). So in the current study the system can achieve the maximum illumination and energy concentration and cut the cost of electricity by requiring fewer solar panels, therefore, it has great significance for research and development.

\section{MATERIALS AND METHODS}

\section{1- Photovoltaic Technology}

Solar energy is considered the most abundant and convenient source of renewable energy, which can be harnessed by photovoltaic cells. Photovoltaic cells are the basic of the solar system. The word 
photovoltaic comes from "photo" means light and "voltaic" means producing electricity. Therefore, the photovoltaic process is "producing electricity directly from sunlight". The output power of a photovoltaic cell depends on the amount of light projected on the cell. Time of the day, season, panel position and orientation are also the factors behind the output power. Photovoltaic cells are the smallest part of a solar panel. Solar panel gives maximum power output at the time when sun is directly aligned with the panel. So, in the current design, for the automatic solar tracking system, a modular approach was used to control the solar panel at two axes by using four light dependent resistors (LDRs) as sensors. The signals from sensors received by controller and are used to determine the direction of movement to align the array with the sun. Two types of motor were used to perform this movement based on the signal received from the controller. The panel can rotate on a total degree of $90^{\circ}$ on the vertical level and $180^{\circ}$ on the horizontal level. Figure 1 shows a block diagram of the solar tracking system.

\section{2- Solar Tracking Control System Design}

The solar tracking system uses two motors as the drive source, stepper motor (M1) and DC motor (M2) conducting (Figure 2). The two motors are decoupled, i.e., the rotation angle of one motor does not influence that of the other motor, reducing control problems. Additionally, the tracker does not have the problems common to two axis mechanical mechanisms (that one motor has to bear the weight of the other motor). This implementation minimizes the system's power consumption during operation and increases efficiency and the total amount of electricity generated.

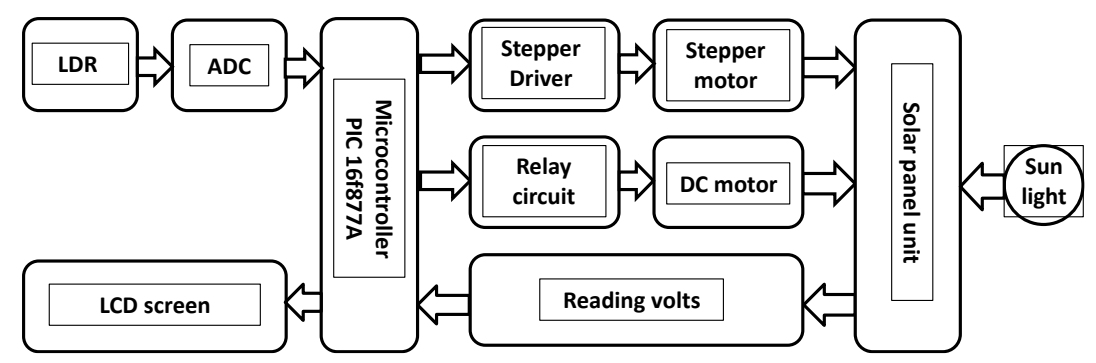

Fig. 1. Block diagram of the solar tracking system. 

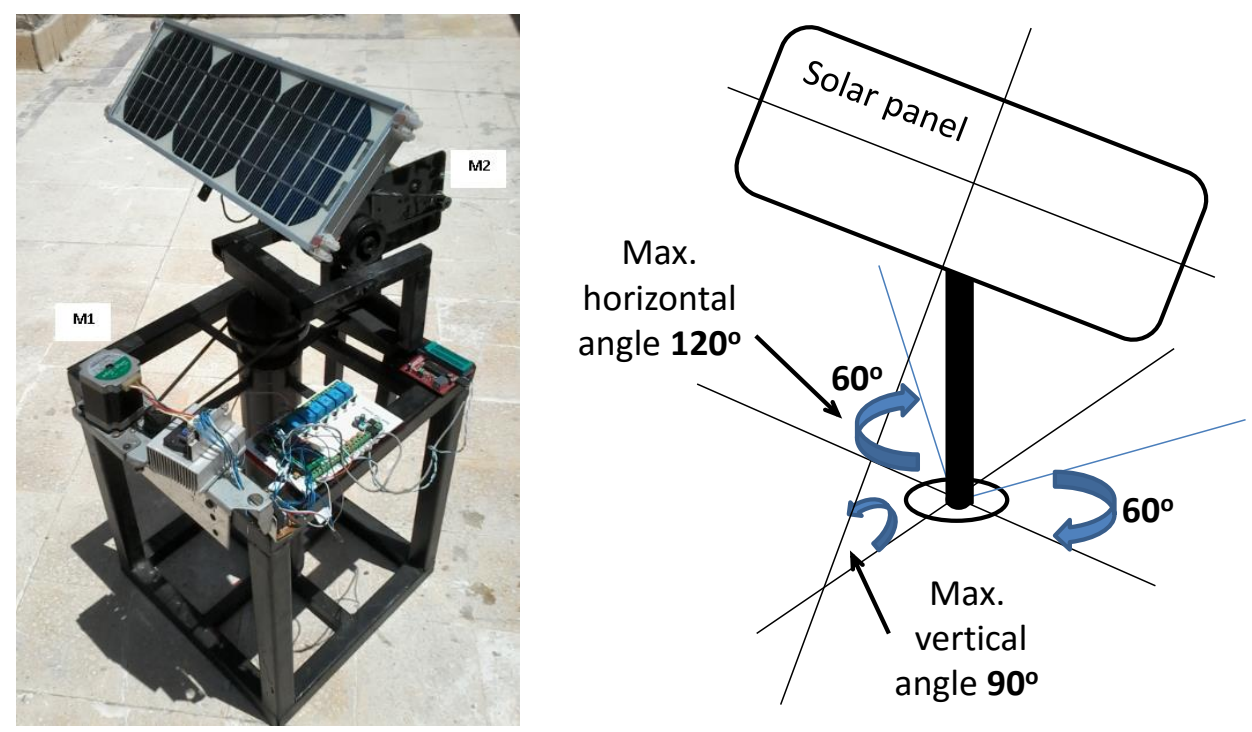

Fig. 2. Photo of the solar tracking control system and the angles of the PV array

Compared to a fixed panel, a mobile photovoltaic (PV) panel driven by a solar tracker is kept under the best possible insolation for all positions of the Sun, as the light falls close to the geometric normal incidence angle. Automatic solar tracking systems (using light intensity sensing) may boost consistently the conversion efficiency of a PV panel, thus in this way deriving more energy from the sun. Technical reports in the USA have shown solar tracking to be particularly effective in summer, when the increases in output energy may reach over $50 \%$, while in autumn they may be higher than 20\%, depending on the technology used (Tiberiu Tudorache and Liviu Kreindler, 2010). Solar tracking systems are of several types and can be classified according to several criteria. A first classification can be made depending on the number of rotation axes. Thus we can distinguish solar tracking systems with a rotation axis, respectively with two rotation axes. Since solar tracking implies moving parts and control systems that tend to be expensive (Tiberiu Tudorache and Liviu Kreindler, 2010). The total amount of PV energy production in the global energy mix has been increasing strongly all over the world in the last decade. This phenomenon has been mainly driven by the promotion of renewable energies, as well as by the well known feed-in tariffs. Although the major part of $\mathbf{P V}$ installations consists in roof 
mounted panels in private, collective or commercial buildings, the amount of large scale PV power plants, from $200 \mathrm{~kW}$ to $10 \mathrm{MW}$ or more is increasing drastically. Such large scale PV power plants already represent nearly $20 \%$ of the total installed PV capacity. Indeed, by reducing of the overall system costs, they are becoming serious alternatives to fossil fuel or nuclear power plants for utilities.

Development of solar panel tracking system has been ongoing for several years. As the sun moves across the sky during the day, it is advantageous to have the solar panels track the location of the sun, such that the panels are always perpendicular with the position of the sun. Available solar trackers in the market are much costly to integrate with solar panel system. In the developing countries where cost is one of the major issues to integrate technologies, solar tracking prototype presented at this paper can provide an effective solution. The major components those are used in the prototype consisted of input, control and output as given below. Figure 3 shows a printed circuit board (pcb) of the system which consists of three parts:

- Input : LDRs (Cadmium Sulphide (CdS) sensors)

- Controller : Microcontroller

- Output : Stepper motor and DC Motor

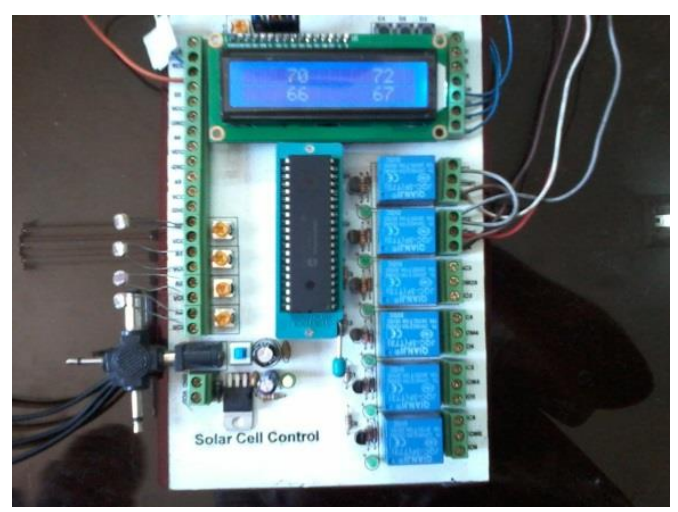

Fig. 3. Printed circuit board (pcb) of the solar tracking system

\section{A. Fixing the LDRs sensors}

The PV panel which used in the experiment, has area of $45 \mathrm{~cm} \times 20 \mathrm{~cm}$, 5 Watt and 0.35 Amp. To command the PV panel motion, four light intensity sensors where used. The tracking sensor is composed of four 
similar (LDRs) sensors, which are located at the four corners of the panel to detect the light source intensity in the four orientations. The four sensors are divided into two groups, east/west and north/south as shown in Figure 4. In the east/west group, the east and west LDRs sensors compare the intensity of received light in the east and west. If the light source intensity received by the sensors is different, the system obtains signals from the sensors' output value in the two orientations. The system then determines which sensor received more intensive light based on the sensor output value. The system drives the stepper motor towards the orientation of this sensor. If the output values of the two sensors are equal, the output difference is zero and the motor's drive voltage is zero, which means the system has tracked the current position of the sun. The north/south sensors track the position of the sun similarly.

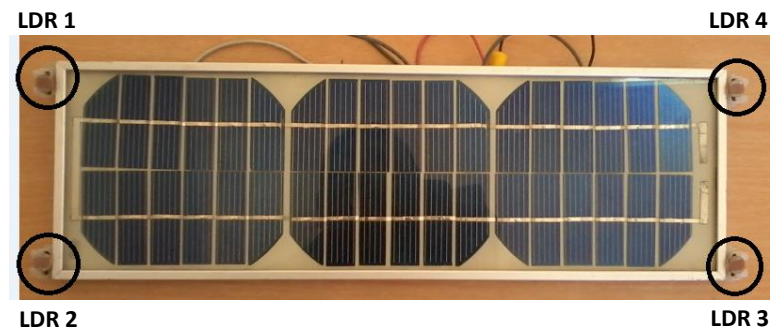

Fig. 4. Fixing the sensors on the panel's corners

\section{B. Microcontroller}

The PIC16f877A microcontroller has been used in the prototype and is considered as the heart of overall system. It requires a 5 volt regulated voltage supply. The transistor $\mathbf{7 8 0 5}$ (voltage regulator) receive 12-18 volts and used to provide fixed 5 volts supply to the microcontroller. PIC16f877A has some features such as Low-power, high-speed Flash/EEPROM technology, Fully static design, wide operating voltage range $(2.0 \mathrm{~V}$ to $5.5 \mathrm{~V})$, low-power consumption, programmable code protection, power saving sleep mode, 100,000 erase/write cycle Enhanced Flash, 10-bit, and up to 8-channel Analog-to-Digital Converter (A/D).

\section{Stepper Motor and Its Driver}

Stepper motors are commonly used in precision positioning control applications. Five characteristics of the stepper motor have been 
considered while choosing stepper motor for the solar tracker prototype. Stepper motor is brushless, load independent, has open loop positioning capability, good holding torque and excellent response characteristics. The stepper motor which used in the experiment is a unipolar, four phase, type 103H7126-1446 FH6-1507 01 SANYO, JAPAN. It takes 3.35 Amp and gives 1.8 Deg. per step.

The stepper motor driver using an integral circuit (IC) STK6713AMK4 unipolar fixed current chopper-type 4-phase stepping motor drive. The driver is used to provide the stepper motor with sufficient current depending on the signals received by the controller. The STK6713AMK4 driver is a hybrid IC which uses a MOSFET power device has the specifications of 24 volts. The excitation sequence signal is active high. The stepper motor with gearbox and its driver that has been used in the prototype are shown in Figure 5.
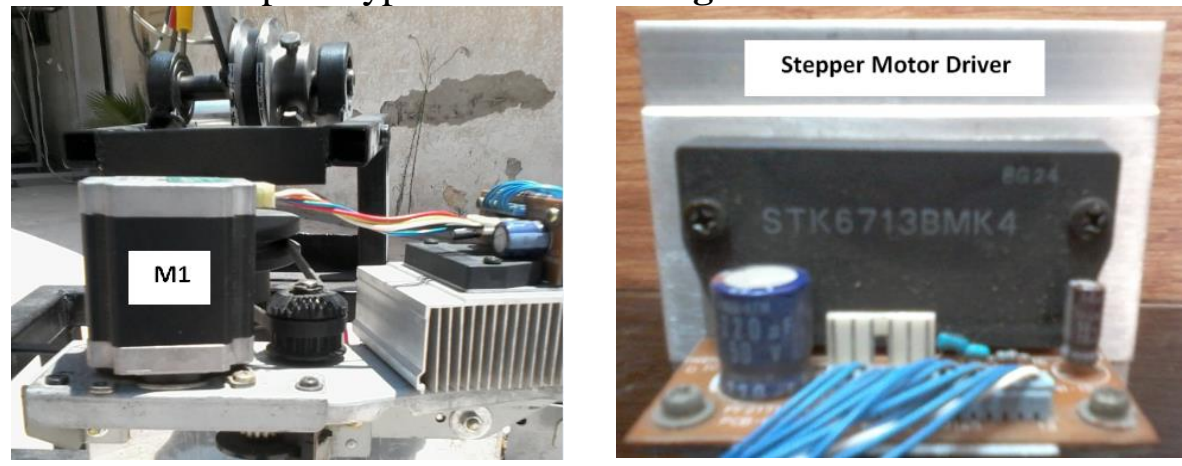

Fig. 5. Stepper motor and its driver

\section{DC Motor Drive System}

The parameters of the DC motor with gearbox used as the movement execution element are: rated voltage $24 \mathrm{~V}$, rated current $2 \mathrm{Amp}$, speed after reduction $40 \mathrm{rpm}$ (Figure 6).

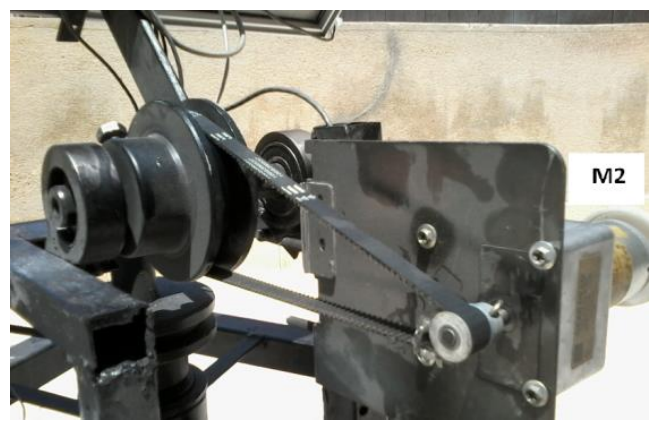


Fig. 6. DC motor with gearbox

\section{OPERATION OF THE SOLAR TRACKER}

Solar tracker provides three ways of operation and control mechanism through the program written in microcontroller. Operational flow chart of the solar tracker is given in Figure 7.

The simulation circuit was designed using proteus professional software version 7.7. The components were picked from the library and connected appropriately as represented in Figure 8. The LDRs represent the sensors connected to pins $6,21,22$, and 23 of the microcontroller. Each sensor connects with a variable resistance to control its sensitivity. The outputs from pins 27, 28, 29 and 30 are connected to stepper motor driver which controls the directions: right and left. Pins 19 and 20 are connected to DC motor which controls the directions up and down.

The compiled program was transferred to the microcontroller after the design completion by right clicking and selecting the program file. Closing and opening the switches cause the motor to change direction while increasing and decreasing the voltage assumed from the panel give different values of power and voltage on the LCD.

\section{Data collected from the system}

The value from PV panel in fixed mode and in tracking mode were measured and obtained at different hours of the day. This experiment was carried out on June, 2014 between 8 am and $6 \mathrm{pm}$ at half hour intervals.

Figure 9. shows the relationship between the power gained from the fixed PV panel and tracking PV panel against day time. It illustrates improvement in efficiency gained with using solar tracking system. From the graph, it can be seen that solar intensity increases with day time to maximum at $13 \mathrm{pm}$ and then starts decreasing. Some fluctuations notable in the graph were as a result of some cloudy sky and abnormal atmospheric condition.

The percentage of solar power output gain is calculated from the following equation: 


$$
\text { Power gain }(\%)=\frac{\text { Power obtained by tracking mode }- \text { power obtained by fixed mode }}{\text { power obtained by fixed mode }} \times 100
$$




\section{The Flow Chart}

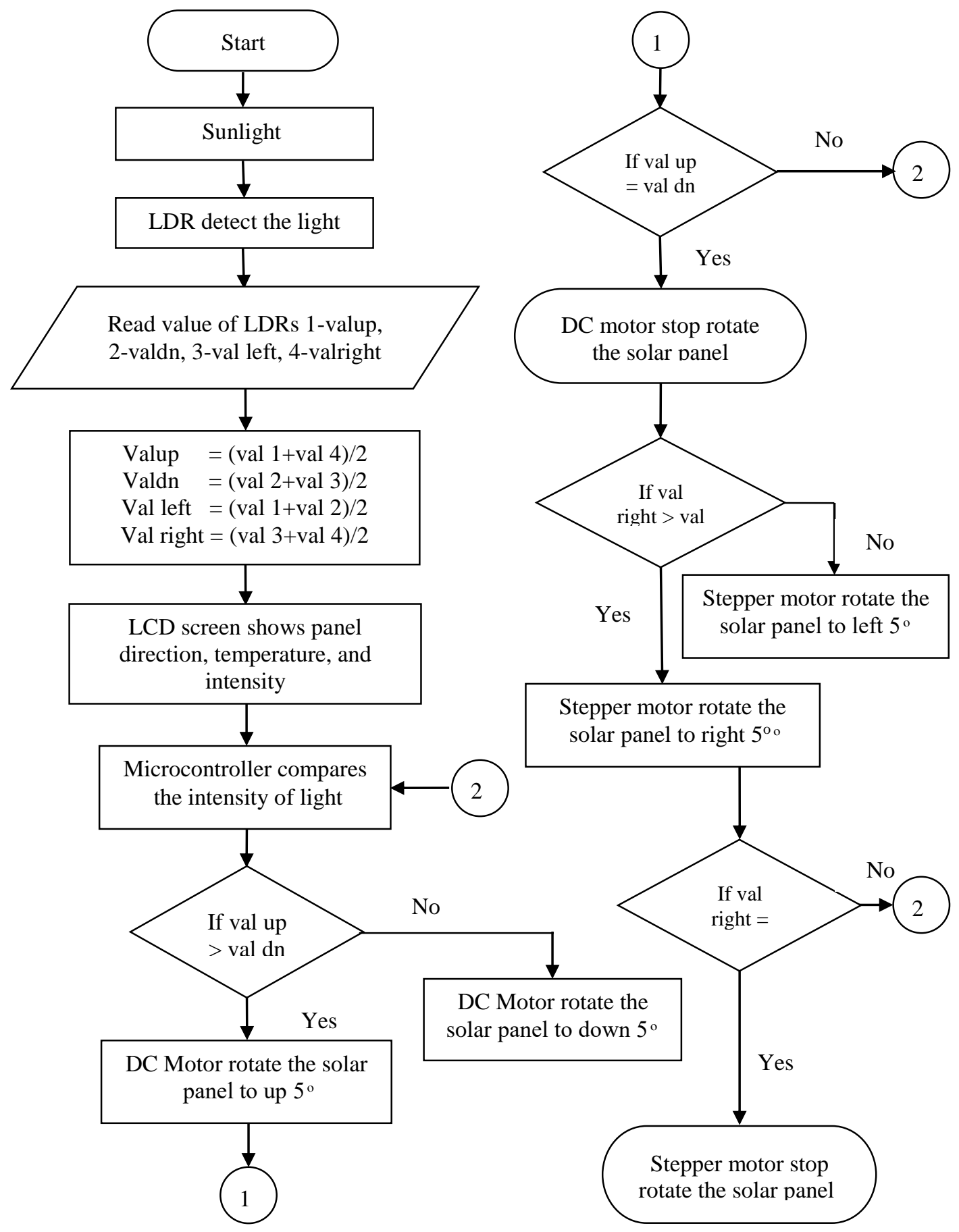

Fig. 7. Flowchart of the solar tracking control system 


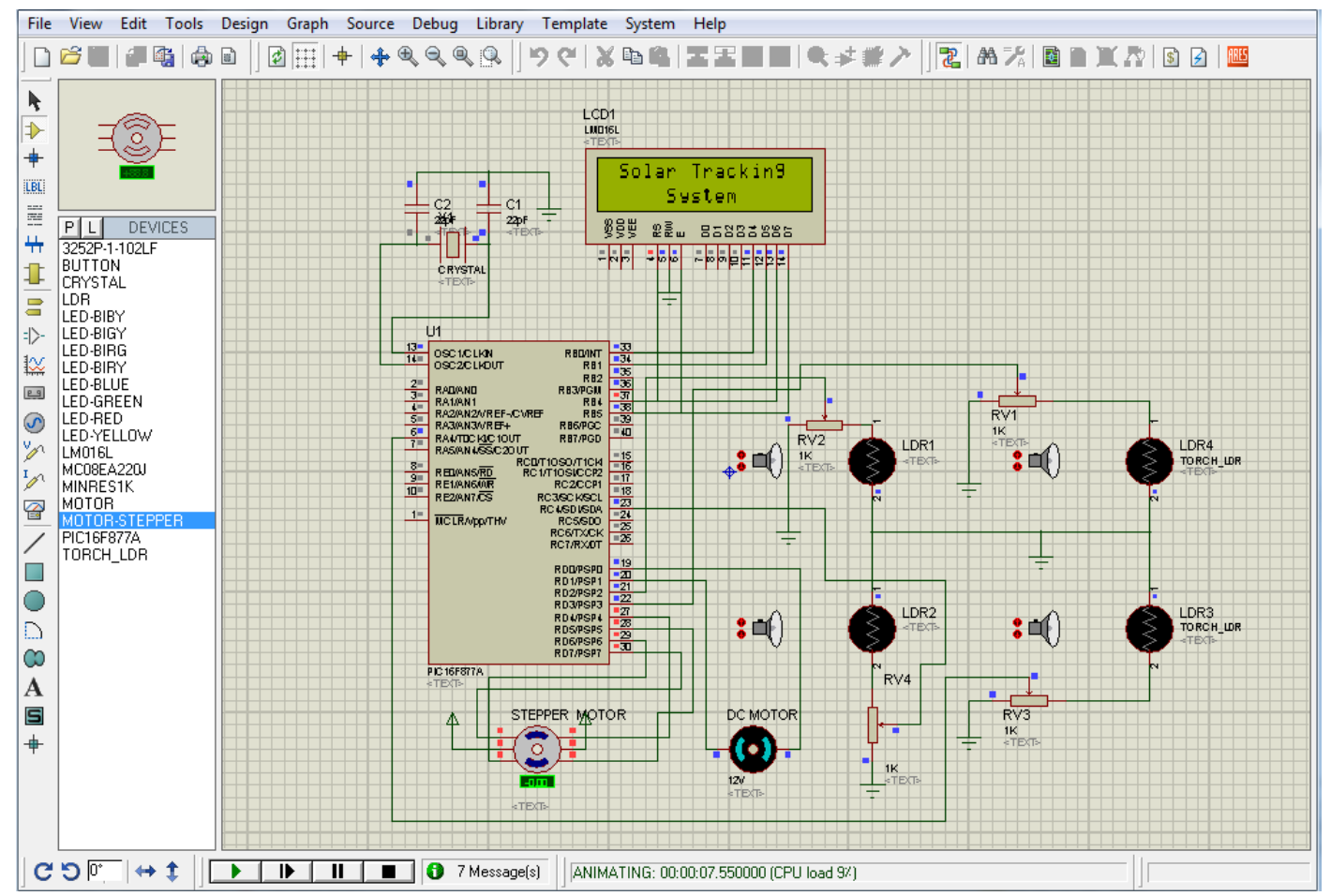

Fig. 8. Schematic diagram of solar tracker circuitry

The percentage increase of solar power output gain approximately riches to $25 \%$ in the morning and afternoon while it was zero percent in the afternoon at 13pm as shown in Figure 10.

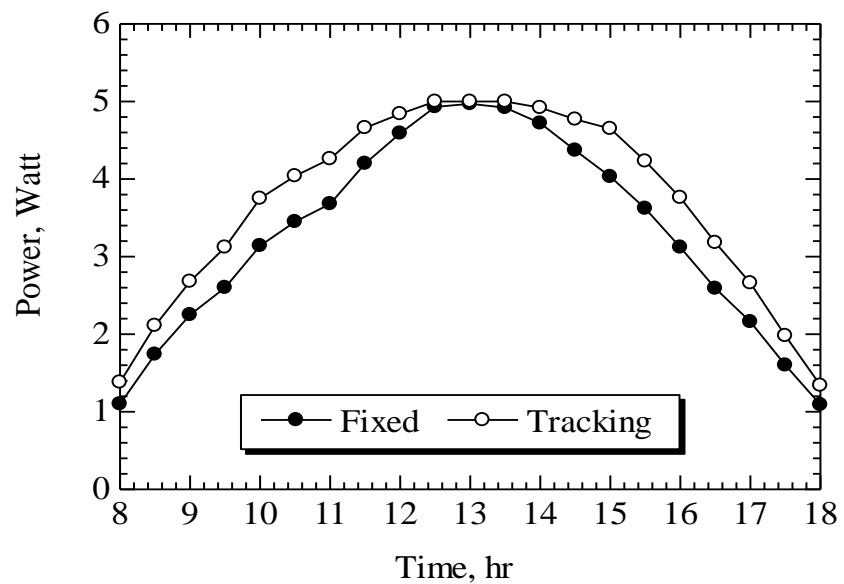

Fig. 9. Power obtained by fixed and automatic tracking system 


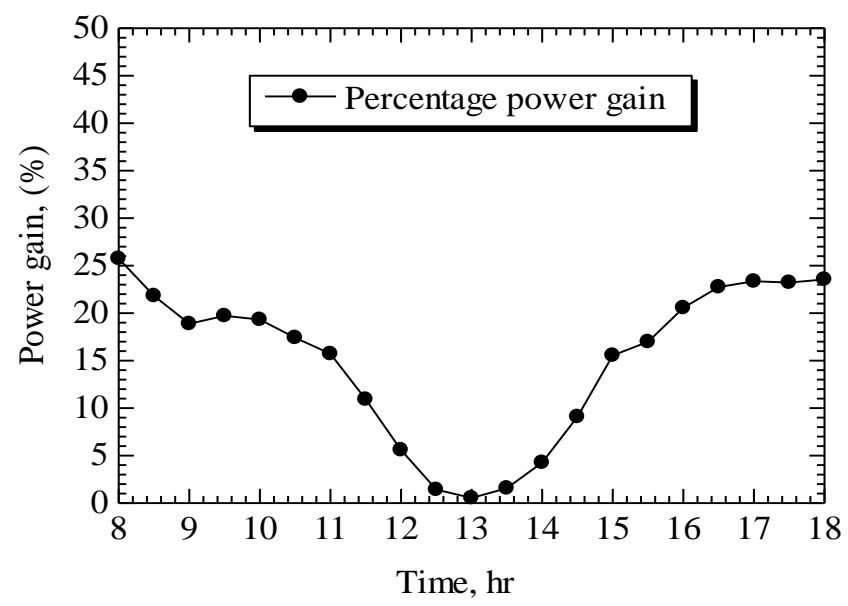

Fig. 10. The percentage of solar power output gain from automatic tracking system

\section{CONCLUSION}

The current paper deals with the design and execution of a solar tracker system dedicated to the PV conversion panels. The operation of the experimental model of the device is based on a DC motor and stepper motor intelligently controlled by a dedicated drive unit that moves a mini PV panel according to the signals received from four simple light sensors. In order to collect the greatest amount of energy from the sun, solar panels must be aligned orthogonally to the sun. For this purpose, a new solar tracking technique based on micro-controller PIC16f877A was implemented and tested in this study. Moreover, the tracker can initialize the starting position itself which reduce the need of any more photo resistors. The use of stepper motor enables accurate tracking of the sun. LDR resistors are used to determine the solar light intensity. Sun tracking generating power system is designed and implemented in real time. The proposed double axis solar tracker device ensures the optimization of the conversion of solar energy into electricity by properly orienting the PV panel in accordance with the real position of the sun. The attractive feature of the designed solar tracker is simple and inexpensive mechanism to control the system. It is also provides lucrative solution for third world countries. It is shown that the sun tracking system using controller with PIC16f877A achieves increasing of about $25 \%$ efficiency improvement over the fixed sun panel system. 


\section{REFERENCES}

Basil M. Hamed and Mohammed S. El-Moghany, 2012. Fuzzy Controller Design using FPGA for Sun Tracking in Solar Array System, I.J. Intelligent Systems and Applic, 2012, 1, 46-52.

Clean Energy Decision Support Centre. (2001-2004) Photovoltaic Project Analysis. Minister of Natural, Resources Canada.

El-Ashry, M., 2010. Renewables 2010 Global Status, Report, (Paris: REN21 Secretariat). Copyright Deutsche, (GTZ) GmbH.

Integral circuit PIC16F87XA datasheet, 2003 Microchip Technology Inc. Integral circuit STK6713AMK4 datasheet.

Joydev Ghosh, Abhishek Dey and Supratim Sen, 2013. The Design of Electronics Based Solar Tracking System, the international Journal of Enhanced Research in Science Technology \& Engineering, ISSN: 2319-7463 Vol. 2, Issue 8, August-2013, pp: 68-71.

M.A. Panait and T Tudorache, 2008. A Simple Neural Network Solar Tracker for Optimizing Conversion Efficiency in Off-Grid Solar Generator. Intl. Conf. on Renewable Energy and Power quality, no. 278, March, 2008.

Md. Tanvir Arafat Khan, S.M. Shahrear Tanzil, Rifat Rahman, SM Shafiul Alam, 2010. Design and Construction of an Automatic Solar Tracking System, $6^{\text {th }}$ International Conference on Electrical and Computer Engineering, ICECE 2010, 18-20 December 2010, Dhaka, Bangladesh, pp. 326-329.

Parallax, 2004. Experiments with Renewable Energy, Student Guide. version1.

Piao, Z.G. Park, J. M. Kim, J. H. Cho, G. B. Baek, H. L, 2005. A study on the tracking photovoltaic system by program type, Intl. Conf. on Electrical Machines and Systems, Vol. 2, Sept. 27-29, 2005, pp. 971-973.

Regulator Transistor 7805 datasheet. 
Tiberiu Tudorache1 and Liviu Kreindler, 2010. Design of a Solar Tracker System for PV Power Plants, Acta Polytechnica Hungarica Vol. 7, No. 1, 2010 pp. 23-39.

Tse, K. K., M. T. Ho, H. Chung, and S. Y. Hui, 2002. A Novel Maximum Power Point Tracker for PV Panels Using Switching Frequency Modulation. IEEE TRANSACTIONS ON POWER Electronics, Vol. 17, No. 6, November 2002.

Zhang Xinhong, Wu Zongxian, Yu Zhengda, 2007. Intelligent Solar Tracking Control System Implemented on an FPGA, Third Prize, Institute of Electrical Engineering, Yuan Ze University.

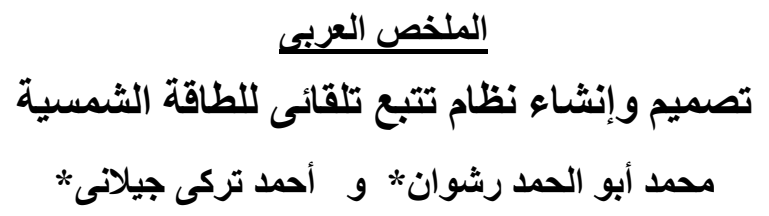

تعثبر أزمة الطاقة هي القضية الأكثر أهمية في عالم اليوم وفى مصر بصفة خاصة حيث زئ زيادة

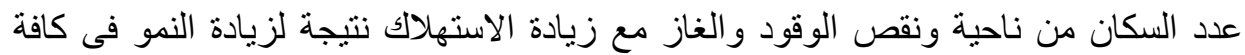

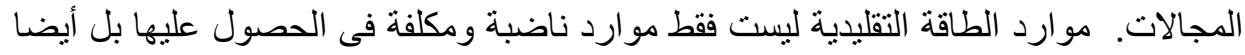

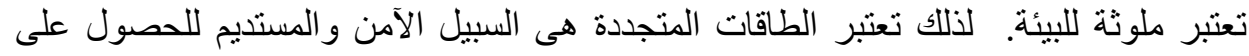
طاقة نظيفة وتقليل الاعتماد على المصادر التقليدية. تكتسب الطاقة الثمسية أهمية متز اليدة خاصنة

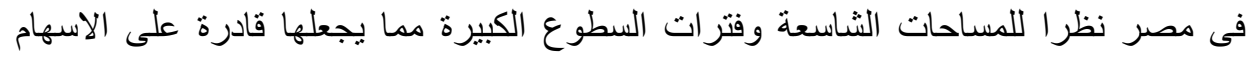
بنصيب كبير من الطاقات المستخدمة. تحويل الطاقة الثمسية إلى طاقة كهربائية باستخدام الخلايا الثمسية ماز الت مكلفة وغير فعالة لذلك يتم تطبيق آليات مختلفة لزيادة كفاءة الخلايا

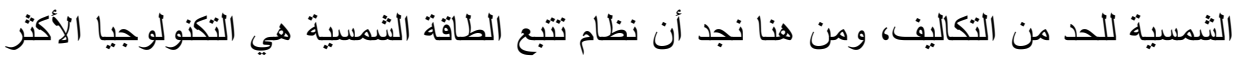

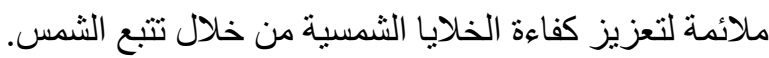

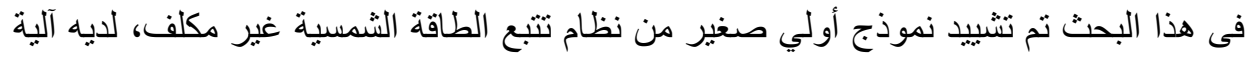

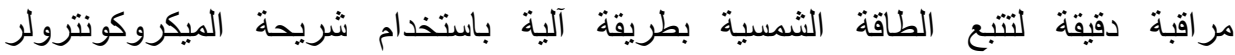

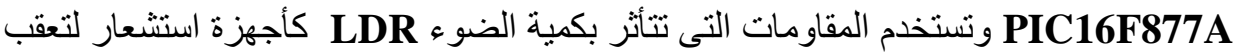

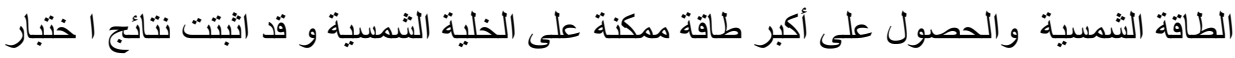

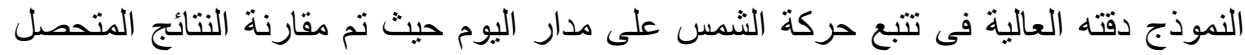

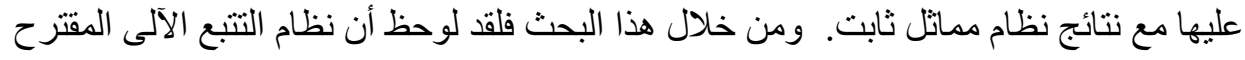

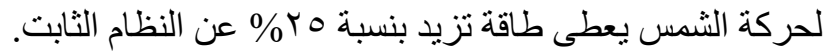

*مدرس بقسم الهندسة الزراعية والنظم الحيوية ـ كلية الزراعة - جامعة الاسكندرية. 